\title{
Identification of serum cytokines as markers in women with recurrent pregnancy loss or miscarriage using MILLIPLEX analysis.
}

\author{
Noura AlJameil ${ }^{1 *}$, Hajera Tabassum ${ }^{1}$, Huda AlMayouf ${ }^{2}$, Amal Alshenefy ${ }^{2}$, Maha Mohammed \\ Almohizea $^{3}$, Mir Naiman $\mathrm{Ali}^{4}$ \\ ${ }^{1}$ Department of Clinical Laboratory Sciences, King Saud University, Riyadh, Kingdom Saudi Arabia \\ ${ }^{2}$ Section of Obstetrics and Gynecology, King Saud Medical City Hospital, Riyadh, Kingdom of Saudi Arabia \\ ${ }^{3}$ Department of Microbiology, College of Medicine, King Khalid University Hospital, King Saud University, Riyadh, \\ Kingdom of Saudi Arabia \\ ${ }^{4}$ Division of Microbiology, Riyadh Municipality Central Area labs for Environmental Health, Riyadh, Kingdom of \\ Saudi Arabia
}

\begin{abstract}
Recurrent pregnancy loss (RPL) is loss of three or more consecutive pregnancies during first trimester of pregnancy. The etiology in most of the recurrent miscarriages is unknown. The main cause of recurrent miscarriage is the abnormal karyotype. Apart from this, number of factors are responsible like defects in maternal endometrium, placenta, and autoimmune malfunctions. Additionally exaggerated immune response by the cytokines seems to play a crucial role in the termination of pregnancies. Analysis of serum cytokines in women with recurrent pregnancy loss would add to better and clear understanding of the role of cytokines in miscarriage. The study enrolled 60 pregnant women aged 26-48 y; the RPL group comprised of 30 women with first trimester miscarriage and the control group included 30 women with first trimester successful pregnancy with no history of miscarriage. Serum cytokines were measured by Milliplex Luminex with XMAP (Multianalyte profiling) technology. Cytokines like tumor necrosis factor- $\alpha$, interferon- $\gamma$, interleukin- 8 increased and interleukin- 6 decreased significantly $(\mathbf{p}<\mathbf{0 . 0 0 1})$ in RPL group compared to control. There was no significant correlation between cytokines and fertility hormones like follicle stimulating hormone and luteinizing hormone whereas interferon- $\gamma$ was strongly correlated with luteinizing hormone and prolactin in miscarriage group. Our data suggests that cytokines the immunological mediators are major determining factors for poor pregnancy outcomes. Though fertility hormones play role in occurrence and maintenance of pregnancy, termination of pregnancy could be due to altered immune response and there is no correlation of tumor necrosis factor- $\alpha$, interleukins 6 and 8 with follicle stimulating hormone, luteinizing hormone and prolactin hormones.
\end{abstract}

Keywords: Cytokines, Recurrent miscarriage, Fertility hormones.

Accepted on October 3, 2018

\section{Introduction}

Miscarriage is a common clinical reproductive problem occurring in approximately $1-2 \%$ of pregnancies [1]. It is also termed as recurrent miscarriage (RM) or recurrent pregnancy loss (RPL) when there are three or more consecutive miscarriages during first trimester prior to 20 weeks gestation [1]. The first trimester of pregnancy begins on the first day of last period and until the end of week 12. The cause of RPL has been widely investigated, including parental and fetal chromosomal abnormalities, abnormalities in uterus, antiphospholipid syndrome (APS), thrombophilia etc. Beside these, coagulation disorders, autoimmune defects, endocrine malfunctions like polycystic ovarian syndrome and untreated diabetes etc., also play a predominant role in pathophysiology of RPL [2]. The etiology in approximately $50 \%$ of cases of RM is unknown. Despite intensive and thorough investigations, no identifiable cause could be found in most of the cases. Hence it has been postulated that exaggerated maternal immune response could be suggested as one of the underlying cause for proportion of these repeated pregnancy losses. Cytokines belong to a diverse family of small, soluble proteins that are expressed by several cell types and tissues and act as immunologic mediators. These proteins exhibit pleiotropy and functional redundancy, up and down-regulating one another to result in complex networks involved in the establishment and 
maintenance of pregnancy and complications such as miscarriage and preeclampsia $[3,4]$.

Normal pregnancy has been characterized as Th2-dominant state [5]. During the early stages of pregnancy, cytokines are considered to expedite important immune modulation resulting in a switch to the type 2 response that maintains the normal and safe run of pregnancy [6]. Alteration in levels of certain cytokines could be one of the probable cause for the onset and recurrence of RPL in females. The exact mechanism by which abnormal immune factors cause recurrent miscarriage is uncertain, but may involve modulation or imbalance between the various cells of the immune systems, especially the $\mathrm{T}$ cell subgroups.

The major immune cells responsible for production of cytokines are the $\mathrm{CD}^{+}{ }^{+} \mathrm{T}$-helper cells. They are typically divided into three functional subsets-Th1, Th2 and Th0. Interferon gamma (INF- $\gamma$ ), interleukin (IL-2) and tumour necrosis factor (TNF- $\beta$ ) are formed from Th1 cells and are the main effectors of cell mediated immune response. Humoral immunity or antibody mediated response is accomplished by IL-4, IL-5, IL-6 and IL-10 which are the main effectors cells synthesized by Th2 subtype. Another class of cytokines that participates in the inflammatory response includes the proinflammatory cytokines like IL-1, TNF- $\alpha$ and IL-6 produced by macrophages [7]. The most important inflammatory marker identified in the cytokine cascade is the TNF- $\alpha$. The enhanced production of TNF- $\alpha$ has been linked to the pathogenesis of various diseases including rheumatoid arthritis, diabetes mellitus, and obesity [8]. Successful pregnancy depends on the balance between the Th1 and Th2 which are involved in fetal growth and development [9]. In early pregnancy TNF- $\alpha$, IL- $1 \beta$, and IL- 6 are some of the fundamental cytokines that functions in blastocyst implantation and parallel has adverse effect on first-trimester losses. Earlier investigation on healthy pregnant women had found reduction of proinflammatory cytokines, such as TNF- $\alpha$, IL- $1 \beta$ and increase of counter-regulatory cytokines such as IL-10 [10]. IL-6 is a multifunctional Th2-type cytokine produced by immune cells, fibroblasts, endothelial cells, adipocytes, and myocytes [11]. The role of IL-6 expression during pregnancy, as well as its predictive value for pregnancy outcome is unclear

Importantly, luteal phase defect is also one of the contributing factors for RPL leading to endometrial retardation. The exact mechanism of endometrial retardation resulting in recurrent miscarriage is not yet elucidated. Progesterone, at concentrations comparable with those present at the maternofetal interface during pregnancy is a potent inducer for IL-4, IL-5 and macrophage colony stimulating factor (M-CSF) production by $\mathrm{T}$ cells [12]. Hormones like leutinising hormone (LH) and follicle stimulating hormone (FSH) also have an effect on endometrium. LH hypersecretion is thought to exert a direct adverse effect on endometrial function [13].

Greater understanding of the effects of cytokines will give insight into normal regulatory processes in tissues and may lead to therapeutic advances. Keeping in view of the above and disparity of the role of cytokines in RPL, the present study was intended with following objectives a) to assess serum cytokines concentration in maternal serum of pregnant women with RPL in comparison with normal pregnancy, b) to investigate the correlation between cytokines and fertility hormones like FSH, $\mathrm{LH}$ and prolactin and c) to investigate the cytokine profile including IL-6, IL-8, INF- $\gamma$ and TNF- $\gamma$ levels in serum of women with recurrent pregnancy loss.

\section{Materials and Methods}

\section{Study population}

This study was carried out in the Department of Clinical laboratory Sciences, College of Applied Medical Science, King Saud University in collaboration with Section of Obstetrics and Gynecology, King Saud Medical City Hospital, Riyadh from September 2015 to March 2016. The hospital's ethics committee has approved the study and informed consent was obtained from patients before blood sampling. The sample selection was based on random sampling procedure. From a total population of 100 pregnant women, two groups were selected in the age group of 26-48 years and based on history of recurrent miscarriage. 30 normal pregnant women were taken as control (group-I) and another 30 women with recurrent pregnancy loss or miscarriage with $\mathrm{P} 0+7, \mathrm{P} 1+5$ etc., were grouped as RPL group (Group II). Gestational age of the patients was calculated using the first day of the woman's last menstrual period and confirmed with the gestational age measured by ultrasonography.

\section{Inclusion criteria}

Control group: Pregnant women with normal blood pressure (BP), absence of proteinuria, normal renal function and without any other systemic or endocrine disorder. These women had no previous history of miscarriage.

RPL group: Females enrolled under RPL group included those with three or more consecutive miscarriages during first trimester (generally upto week 12) and those with miscarriage before gestational age of 20 week as determined by ultrasound. These subjects did not present with any thyroid disease, congenital or acquired thrombophilic disorders and uterine anomalies.

\section{Exclusion criteria}

All women with gestational diabetes, diabetes mellitus, history of smoking or hypertension, proteinuria, renal, cardiovascular, hepatic or endocrine disease, metabolic disorders and current infection were excluded from the study.

\section{Collection of blood samples and preliminary biochemical analysis}

On admission, five milliliter of blood was drawn from each subject participated in the study in metal free sterile vacutainers. Blood samples obtained were then kept at room 
temperature for $30 \mathrm{~min}$ and centrifuged at $3000 \mathrm{rpm}$ for $15 \mathrm{~min}$ to extract the serum. The serum samples were transferred in eppendorf tubes and stored at $-80^{\circ} \mathrm{C}$ until analysis. Basic biochemical tests including complete blood count was measured in auto analyzer CellDyne 3700 (STA compact, Mediserv, UK).

\section{Analysis of fertility profile}

Measurement of LH, TSH (Thyroid Stimulating Hormone) and prolactin was done using Roche Elecsys 2010 Modular Analytics E170-Cobas e 411 utilizing electrochemiluminescence immunoassay (Roche Diagnostics, Germany).

\section{Measurement of serum cytokines by Milliplex Luminex assay}

Serum concentration of cytokines - IL-6, IL-8, INF- $\gamma$ and TNF$\alpha$ were performed using quantitative Milliplex Luminex assay using MILLIPLIX Map kit-Human cytokine panel magnetic bead panel (HCYTOMAG-60K) Millipore. In brief, serum samples were prepared as per the instructions and standard in range from 3.2 to $2000 \mathrm{pg} / \mathrm{ml}$. 96 well plates were pre-wet with $25 \mu \mathrm{l}$ assay buffer (provided by the manufacturer) for $10 \mathrm{~min}$ and then aspirated using a vacuum manifold. Standards and serum samples were added to appropriate wells, followed by the addition of assay beads and assay buffer ( $25 \mu \mathrm{l}$ each). Plates were incubated overnight for $16-18 \mathrm{~h}$ with mild agitation at $4^{\circ} \mathrm{C}$. Detection antibodies were added to each well, and incubated for $1 \mathrm{~h}$ at room temperature (RT), the fluorescent conjugate streptavidin-phycoerythrin was added to each well and plates incubated for $30 \mathrm{~min}$ at RT. The samples were run and read on Luminex200TM with Xponent software.

\section{Statistical analysis}

Data was analysed using SPSS software. Clinical characteristics and biochemical parameters of patients were compared with control group by one way ANOVA followed by Holm-Sidak test. Pearson's correlation was performed to identify the correlation between different cytokines and fertility hormones.

\section{Results}

Comparison of the serum cytokines and fertility hormones in both the groups are presented in Table 1. Mean values of cytokines like IL-8, IFN- $\gamma$ and TNF- $\alpha$ were shown to increase in RPL group compared to control cases. These levels were found to increase significantly $(\mathrm{p}<0.001)$ upon ANOVA followed by Holm-Sidak test. In contrast the levels of IL-6 decreased significantly in RPL group compared to control. Analysis of fertility hormones; prolactin, FSH, LH also revealed increased levels of these hormones in RPL group compared to control $(\mathrm{P}<0.001)$. Table 2 depicts the correlation between cytokines and other variables like fertility profile performed by Pearson's correlation. There was no significant correlation between levels of cytokines and fertility hormones. In the control group negative correlation was observed between LH and IL-6 and positive correlation between LH with TNF- $\alpha$. The association of IL- 6 and TNF- $\alpha$ with LH was statistically significant at $\mathrm{p}<0.05$. The same correlation was not observed in RPL group. INF- $\gamma$ exhibited positive association with LH $(\mathrm{p}<0.05)$ and prolactin hormones at $\mathrm{p}<0.001$. The correlation between cytokines and fertility hormones was not significant in RPL group except the correlation between LH and prolactin with INF- $\gamma$.

In order to establish the inter relationship between cytokines and fertility hormones in RPL group, Pearson's correlation was performed among all the variables and represented in Table 3. It was found that IL-6 and IL- 8 demonstrated negative correlation in both the groups but statistically significant $(p<0.001)$ in control group and non-significant in RPL group. None of the inter relationship between these variables were significant in RPL group as well as in control. The correlation between INF- $\gamma$ with fertility hormones in RM (recurrent miscarriage) is depicted in Figure 1.

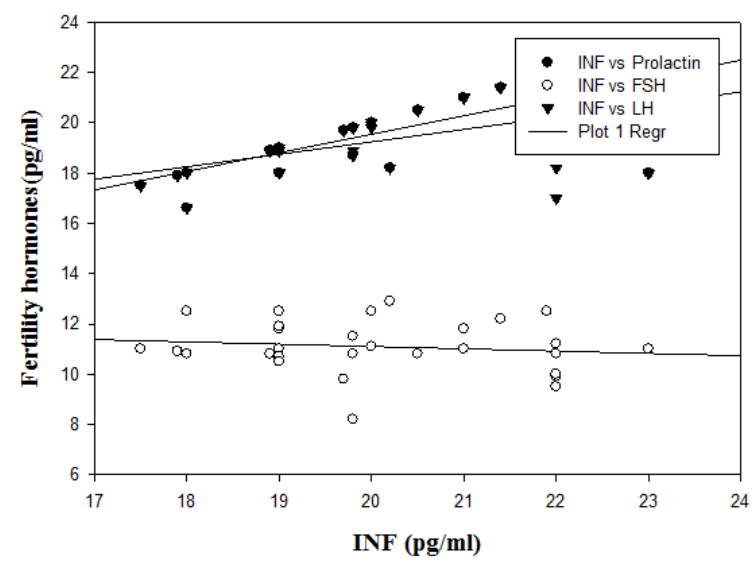

Figure 1. Multiple scatter plot with regression showing correlation between Interferon and fertility hormones in RM group.

Table 1. Levels of serum cytokines and fertility hormones in control and cases.

\begin{tabular}{llll}
\hline & Control & RPL group & $\mathbf{t}(\mathbf{p})$ \\
\hline $\mathrm{IL}-6(\mathrm{pg} / \mathrm{ml})$ & $90.89 \pm 1.47$ & $78.59 \pm 1.58$ & $31.14^{*}$ \\
\hline $\mathrm{IL}-8(\mathrm{pg} / \mathrm{ml})$ & $67.65 \pm 1.17$ & $76.71 \pm 1.79$ & $23.18^{*}$ \\
\hline $\mathrm{INF}-\mathrm{Y}(\mathrm{pg} / \mathrm{ml})$ & $15.20 \pm 1.31$ & $20.10 \pm 1.50$ & $13.38^{*}$ \\
\hline TNF- $\alpha(\mathrm{pg} / \mathrm{ml})$ & $183.77 \pm 3.16$ & $301.71 \pm 5.30$ & $104.52^{*}$ \\
\hline Prolactin $(\mathrm{ng} / \mathrm{ml})$ & $15.25 \pm 1.31$ & $19.65 \pm 1.51$ & $12.03^{*}$ \\
\hline FSH $(\mathrm{mlU} / \mathrm{ml})$ & $7.35 \pm 1.33$ & $11.09 \pm 1.02$ & $12.16^{*}$ \\
\hline LH $(\mathrm{mlU} / \mathrm{ml})$ & $17.80 \pm 0.81$ & $19.30 \pm 1.45$ & $4.72^{*}$ \\
\hline${ }^{*}$ means $\mathrm{p}<0.001$ & & & \\
\hline
\end{tabular}


Table 2. Correlation between cytokines and fertility hormones in control and RPL group.

\begin{tabular}{|c|c|c|c|c|c|c|}
\hline & \multicolumn{3}{|l|}{ Control } & \multicolumn{3}{|l|}{ RPL group } \\
\hline & Prolactin & FSH & LH & Prolactin & FSH & LH \\
\hline & $r(p)$ & $r(p)$ & $r(p)$ & $r(p)$ & $r(p)$ & $r(p)$ \\
\hline IL-6 & $-0.03(0.86)$ & $-0.12(0.5)$ & $-0.38\left(0.03^{* *}\right)$ & $0.17(0.34)$ & $0.035(0.85)$ & $-0.32(0.08)$ \\
\hline IL-8 & $0.07(0.71)$ & $0.16(0.35)$ & $0.13(0.46)$ & $-0.07(0.64)$ & $-0.33(0.07)$ & $0.32(0.08)$ \\
\hline INF-Y & $1.00(0.00)$ & $-0.08(0.65)$ & $-0.18(0.31)$ & $0.73\left(0.00003^{*}\right)$ & $-0.13(0.4)$ & $0.5\left(0.003^{* *}\right)$ \\
\hline TNF- $\alpha$ & $0.05(0.78)$ & $-0.28(0.13)$ & $0.36\left(0.04^{* *}\right)$ & $0.13(0.46)$ & $-0.04(0.82)$ & $0.16(0.38)$ \\
\hline
\end{tabular}

"means $p<0.001 ;{ }^{* *} p<0.05$

Table 3. Interrelationship between cytokines in RPL group.

\begin{tabular}{lll}
\hline Cytokines & $\mathbf{r}$ & $\mathbf{p}$ \\
\hline IL-6 and IL-8 & -0.07 & 0.67 \\
\hline IL-6 and INF- $\gamma$ & -0.11 & 0.56 \\
\hline IL-6 and TNF- $\alpha$ & 0.24 & 0.19 \\
\hline IL-8 and INF- $\gamma$ & 0.3 & 0.1 \\
\hline IL-8 and TNF- $\alpha$ & -0.15 & 0.4 \\
\hline INF- $-\gamma$ and TNF- $\alpha$ & 0.1 & 0.59 \\
\hline
\end{tabular}

\section{Discussion}

The present study reported increased levels of INF- $\gamma$ and TNF$\alpha$ in peripheral serum of women suffering from miscarriage and TH 2 type cytokines (IL-6) in healthy pregnant women. Serum levels of IL- 6 was high whereas INF- $\gamma$ and TNF- $\alpha$ were low in normal pregnant women. The levels of these cytokines are reversed in women with recurrent pregnancy loss or miscarriage group. There are various mechanism through which TNF- $\alpha$ may account for pregnancy loss. It enhances the production of prostaglandins that leads to uterine contractions. Another mechanism is the implication of TNF- $\alpha$ in apoptosis. Increased levels of TNF- $\alpha$ has a negative effect on the implantation of embryo and adversely decreases the blood flow to the embryo leading to thrombosis in the blood vessels. TNF$\alpha$ plays a pivotal role in the cytokine cascade and it is a therapeutic target in many inflammatory diseases. Pregnancy success appears to rely on a discrete balance between the cytokines Th1 and Th2, which are involved in fetal growth and development. TNF- $\alpha$, IL- $1 \beta$, and IL- 6 are some of the fundamental cytokines in early pregnancy. As pregnancy progresses, high TNF- $\alpha$ concentration have been related to the development of complications like preeclampsia and gestational diabetes mellitus (GDM) [14].

Amongst the proinflammatory cytokines-INF- $\gamma$ was among the first cytokine identified to be secreted in the uterus during early stages of pregnancy. It is abundantly produced by uterine natural killer cells in maternal endometrium. INF- $\gamma$ has varied roles in cellular processes including activating innate and adaptive immune responses, inhibiting cell proliferation, and inducing apoptosis. It is also crucial in immune response. Th1 development is also enhanced by IFN- $\gamma$ [15]. Increased levels of serum TNF- $\alpha$ and decreased IL- 6 observed in the present study are in accordance with previous reports $[16,17]$. Similar result of IL-8 was observed in previous report by Hattori et al. with disparity in levels of serum IL-6 in the present study [17].

Investigating on the role of cytokines, we found significant change in levels of serum cytokines in women with recurrent pregnancy loss compared to normal pregnant women thus indicating that increased levels of cytokines like INF- $\gamma$ and TNF- $\alpha$ are responsible for miscarriage. The main underlying cause for RPL identified through this study is the increased cytokines. Similar results for INF- $\gamma$ were associated with poor IVF pregnancy outcome [18]. In order to know whether cytokines exert their effect alone or in harmony with fertility hormones, interrelationship studies between fertility hormones and cytokines were done. It was found that there was no significant association between them except for INF- $\gamma$. Among all the cytokines studied INF- $\gamma$ exhibited statistically significant positive correlation with prolactin $(\mathrm{r}=0.73$; $\mathrm{p}<0.0001)$ and with $\mathrm{LH}(\mathrm{r}=0.5 ; \mathrm{p}<0.05)$.

The serum levels of prolactin, FSH and $\mathrm{LH}$ increased significantly in RPL group compared to control. Hyper secretion of LH tends to be strongly associated with subfertility and early pregnancy failure. Previous studies on assisted conception on hypersecretion of LH found adverse effect of LH on fertility and early pregnancy outcome [19].

The underlying cause of endometrial retardation that leads to miscarriage is not clearly elucidated. Luteal phase defects have been shown to be a contributory factor in recurrent miscarriage. Additionally, LH hypersecretion is thought to exert a direct adverse effect on endometrial function. However, the exact mechanism is again unknown, although there is some suggestion that cytokines may be involved. IL-6 may modulate the interaction between cytokines and gonadal steroid hormones in the proposed feedback of the cytokine-steroid loop within the endometrium. Human trophoblasts express IL-6R and produce IL-6 which induces the production of human chorionic gonadotrophin (HCG) in an autocrine manner indicating a role in implantation and continuation of early 
pregnancy. The exact mechanism by which abnormal immune factors cause recurrent miscarriages is uncertain, but it is speculated that modulation or imbalance between the various cells of the immune system especially the $T$ cell subgroups as evident by the cytokine secretion profile observed in the present study plays a crucial role in etiology underlying RPL [20]. Prolactin is also essential for female reproduction and elevated prolactin levels are associated with ovulatory dysfunction. High prolactin in early follicular growth may inhibit progesterone secretion, which results in luteal phase defects [21]. Interferon- $\gamma$ was found to be emerging factor responsible in etiology of miscarriage in association with $\mathrm{LH}$ and prolactin [22].

The study has some limitations. Women in the age group of 26-48 y were selected with upper age limit maximum below 35 $\mathrm{y}$, but due to limited availability/feasibility and difficulty in collection of samples from women with Recurrent pregnancy losses women above $>35$ age were also included. Moreover, fetal chromosomal abnormalities identifiable by karyotyping and microarray would have added more information to the outcome of the study.

\section{Conclusion}

Increased levels of INF- $\gamma$, LH and prolactin were identified as the underlying cause for recurrent pregnancy loss. Factors responsible for recurrent pregnancy loss are multiple and altered cytokine profile results in loss of pregnancy especially in the early stages of gestation. There is need of the hour that women expecting a pregnancy must be screened to assess the cytokine profile even before conception to avoid loss of pregnancy and to improve the health and social well-being of the females.

\section{Acknowledgement}

The authors are grateful to the Research Center of the 'Center for Female Scientific and Medical Colleges', Deanship of Scientific Research, King Saud University and the Management, King Saud Medical City Hospital, Riyadh, K.S.A.

\section{References}

1. Giannubilo SR, Landi B, PozziV, Sartini D, Cecati M, Stortoni P, Corradetti A, Saccucci F, Tranquilli AL, Emanuelli M. The involvement of inflammatory cytokines in the pathogenesis of recurrent miscarriage. Cytokine 2012; 58: 50-56.

2. Regan L, Rai R. Epidemiology and the medical cause of miscarriage. Baillieres Clin Obstet Gynaecol 2000; 14: 839-854.

3. Li TC, Makris M, Tomsu M, Tuckerman EM, Laird SM. Recurrent miscarriage, aetiology, management and prognosis. Hum Reprod 2002; 8: 463-481.

4. Kharfi A, Giguere Y, Sapin V, Masse J, Dastugue B, Forest JC. Trophoblastic remodeling in normal and pre- eclamptic pregnancies: implication of cytokines. Clin Biochem 2003; 36: 323-331.

5. Romero R, Espinoza J, Goncalves LF, Kusanovic JP, Friel LA, Nien JK. Inflammation in preterm and term labour and delivery. Semin Fetal Neonatal Med 2006; 11: 317-326.

6. Wilczynski JR. Th1/Th2 cytokines balance-yin and yang of reproductive immunology. Eur J Obstet Gynecol Reprod Biol 2005; 122: 136-143.

7. Chaouat G, Ledee-Bataille N, Dubanchet S, Zourbas S, Sandra O. TH1/TH2 paradigm in pregnancy: paradigm lost? cytokines in pregnancy/early abortion: reexamining the TH1/TH2 paradigm. Int Arch Allergy Immunol 2004; 134: 93-119.

8. Raghupathy R. Pregnancy: success and failure within theTh1/Th2/Th3 paradigm. Sem Immunol 2001; 4: 219-227.

9. Patial S, Parameswaran N. Tumor necrosis factor- $\alpha$ signaling in macrophages. Crit Rev Eukary Gene Express 2010; 20: 87-103.

10. Peracoli JC, Rudge MVC, Peracoli MTS. Tumor necrosis factor-alpha in gestation and puerperium of women with gestational hypertension and pre-eclampsia. Am J Repro Imm 2007; 57: 177-185.

11. Wegmann TG, Lin H, Guilbert L, Mosmann TR. Bidirectional cytokine interactions in the maternal-fetal relationship: is successful pregnancy a TH2 phenomenon? Immunol Today 1993; 14: 353-356.

12. Unfried G, Bocskor S, Endler G, Nagele F, Huber JC, Tempfer CB. A polymorphism of the interleukin- 6 gene promoter and idiopathic recurrent miscarriage. Human Reprod 2003; 18: 267-270.

13. Piccinni MP, Scaletti C, Vultaggio A, Maggi E, Romagnani S. Defective production of LIF, M-CSF and Th2-type cytokines by $\mathrm{T}$ cells at fetomaternal interface is associated with pregnancy loss. J Reprod Immunol 2001; 52: 35-43.

14. Saini V, Arora S, Yadav A, Bhattacharjee J. Cytokines in recurrent pregnancy loss. Clinica Chimica Acta 2011; 412: 702-708.

15. Moreli JB, Ruocco AC, Vernini JM, Marilza Rudge VC, Paranhos Calderon IM. Interleukin 10 and tumor necrosis factor-alpha in pregnancy: aspects of interest in clinical obstetrics. ISRN Obst Gyn 2012.

16. Laird SM, Tuckerman EM, Cork BA, Linjawi S, Blakemore AIF, Li TC. A review of immune cells and molecules in women with recurrent miscarriage. Hum Reprod Update 2003; 9: 163-174.

17. Abdullah GA, Mahdi NK. The role of cytokines among women with spontaneous miscarriage. Med J Islamic World Acad Sci 2013; 21: 119-124.

18. Hattori Y, Nakanishi T, Ozaki Y, Nozawa K, Sato T, Sugiura-Ogasawara M. Uterine cervical inflammatory cytokines, interleukin-6 and -8 , as predictors of miscarriage in recurrent cases. Am J ReprodImmunol 2007; 58: 350-357. 
19. Fasouliotis SJ, Spandorfer SD, Witkin SS, Schattman G, Liu HC, Roberts JE, Rosenwaks Z. Maternal serum levels of interferon $\gamma$ and interleukin2 soluble receptor $\alpha$ predict the outcome of early IVF pregnancies. Hum Reprod 2004; 19: 1357-1363.

20. Clifford K, Rai R, Watson H, Franks S, Regan L. Does suppressing luteinising hormone secretion reduce the miscarriage rate? results of a randomised controlled trial. BMY 1996; 312: 1508-1511.

21. Lim KJH, Odukoya OA, Li TC, Cook ID. Cytokines and immuno-endocrine factors in recurrent miscarriage. Hum Reprod Update 1996; 2: 469-481.
22. Kaur R, Gupta K. Endocrine dysfunction and recurrent spontaneous abortion: an overview. Int J Appl Basic Med Res 2016; 6: 79-83.

\section{*Correspondence to}

Noura Al Jameil

Department of Clinical Laboratory Sciences

King Saud University

Kingdom of Saudi Arabia 